\title{
4
}

\section{Ecosystem networks: a spatial concept for integrative research and planning of landscapes}

\section{Paul Opdam}

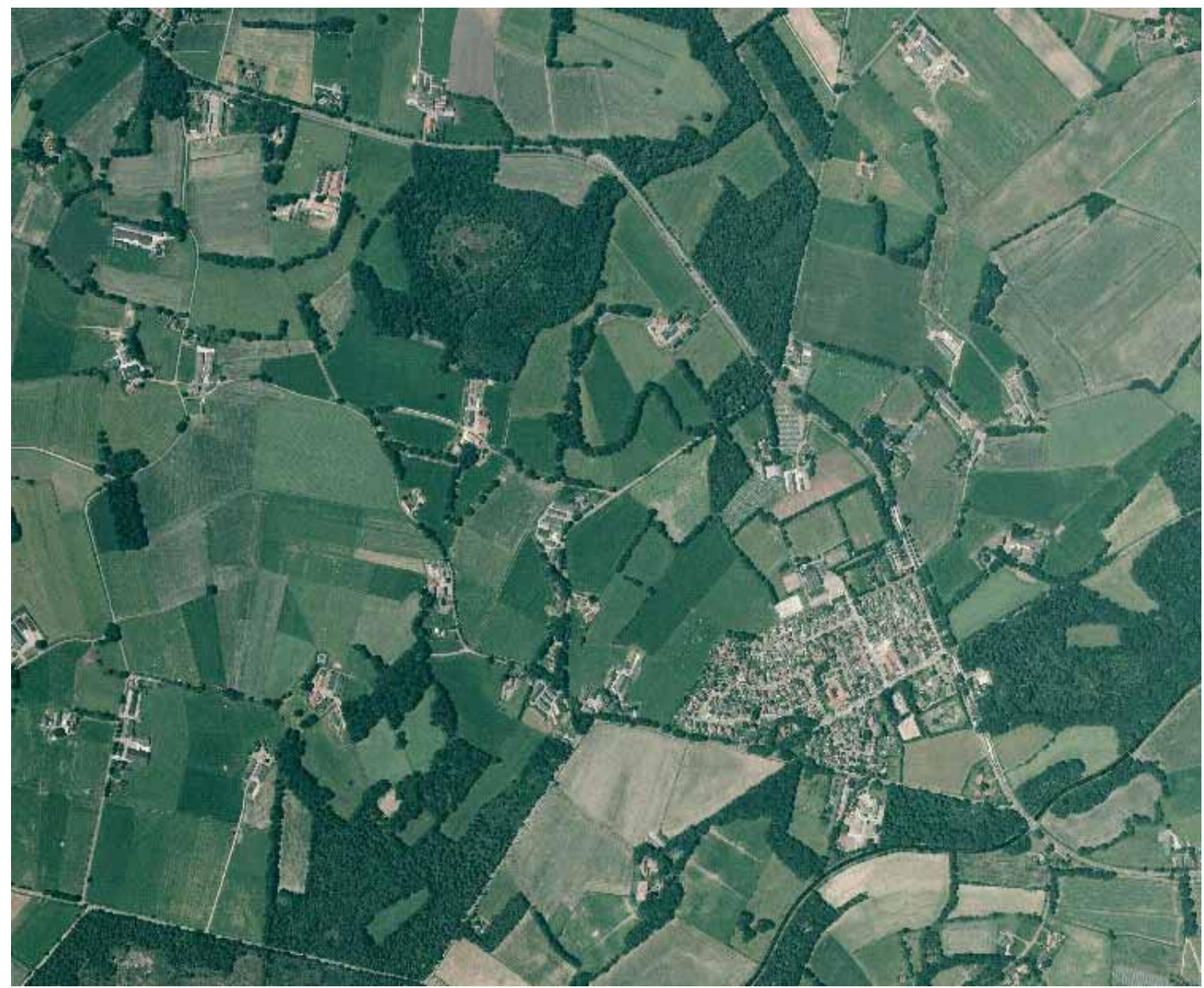

\begin{abstract}
Sustainable development is a widely accepted strategic framework for decisionmaking about the future use of land, but it is not very well adopted in landscape research and planning. Sustainable landscape development aims to ensure the longterm potential of the landscape to sustain ecological, cultural and economic functions. It also entails that local actors take part in planning and design of landscapes. Ecological sustainability, one of the three pillars of sustainable development, is achieved if (regionally chosen) ecological functions are sustained by the landscape structure. I introduce a conceptual model of the landscape based on the principles
\end{abstract}

\# Land Use Planning Group, Department of Environmental Sciences, Wageningen University, Generaal Foulkesweg 13, 6703 BJ Wageningen, The Netherlands. E-mail: Paul.Opdam@wur.nl 
of sustainable landscape development; it includes the ecophysical landscape, the sociological landscape, the economic landscape and the decision-making landscape. Integrative landscape research should aim to identify and quantify the interrelations between these landscape constructs. As a conceptual tool to facilitate research, decision-making and communication, I propose the concept of the ecosystem network. This is a functional network of ecosystem patches, interacting by the exchange of seeds or individuals of plant and animal species, and connected to the surrounding landscape matrix by abiotic fluxes. I hypothesize that the ecosystem network may also be the template of recreation and water management functions. A key feature of the network is that it can sustain similar ecological functioning (e.g. in terms of persistent populations of species) at different spatial configurations. This principle allows flexibility in design and facilitates decision-making in a multifunctional landscape context. As the most important research questions are proposed: identifying the spatial scale of the network in relation to its function, quantifying the potential to deliver goods and services, and methods to facilitate the balancing of competing interests on the short term and long term.

Keywords: sustainable landscape; local stakeholder involvement; decision-making; combining land-use functions; landscape change

\section{Why is most landscape development ecologically not sustainable?}

Let us consider the landscape as a geographical unit, which can be delineated from adjacent landscape units by a typically shaped mosaic of ecosystem types. Let us further assume that this specific landscape structure is the result of the interaction of geographical, ecological and human-induced forces over time (cf. Forman 1995; Steiner 2000). In many parts of the world, modern humans adapt and change the landscape because of using goods and services, delivered by that landscape, which are of economic, social or ecological value to them (Linehan and Gross 1998). These adaptations are a response to changing economic and social needs, while accounting for the natural potential of the landscape. The landscape is developed with a particular purpose in mind, and can therefore be considered as the object of physical planning.

Sustainable development is a widely accepted strategic framework for decisionmaking about the future use of land (IUCN, UNEP and WWF 1992). Sustainable development of landscapes requires that landscape planning aims for "a condition of stability in physical and social systems achieved by accommodating the needs of the present without compromising the ability of future generations to meet their needs" (World Commission on Environment and Development 1987; Ahern 2002). This implies that in decision-making about the future landscape a balance is achieved between ecological, cultural and economic functions in the short term and in the long term (Linehan and Gross 1998), with the purpose that resources of prime importance to future generations are not depleted and destroyed. Hence, sustainable development of landscapes demands that the landscape keeps over time its potential to deliver ecological, social and economic values to present and future generations. This potential must be retained during the process of change, either within the limits of the planning area, or outside in the case that adjacent areas contain sources from which lost values can be re-established. The potential to provide goods and services depends on the ecophysical conditions in the area, for example the area of ecosystems, and their configuration in space. The challenge to science then is to be able to tell which ecophysical conditions will sustain a required level of goods and services. 
The concept of sustainable development is further connected to the notion that local actors involved in planning (e.g. land owners, land managers, conservation groups) should take part in the decision-making. What type of knowledge does decision-making need in order to plan for sustainable development? If decisionmaking has consequences for larger areas than the planning area only, how do stakeholders include and balance the general public interest against their own local interest? What sorts of decisions are involved in determining a balance between functions, and how does the decision group know if the balance is achieved? When we have answers to these questions, we can determine in what form and at which level of detail the knowledge on ecophysical conditions must be provided.

Decision-making for sustainable landscape development then requires that the landscape structure is in balance with the required function, within the boundaries of change set by the requirements of long-term conservation of irreplaceable resources (Haines-Young 2000). This should also hold for the ecological functions being in balance with the landscape structure (ecological sustainability). However, ecological sustainability is not yet well developed in landscape planning (Termorshuizen et al. unpubl.). The explicit inclusion of ecological principles in planning is quite a recent advancement (Ahern 2002). Steiner (2000) introduces 'ecological planning', defined by "the use of biophysical and socio-cultural information to suggest opportunities and constraints for decision making about the use of landscapes". His handbook takes ecological sustainability as a basic goal for landscape development. Although Steiner pays extensive attention to involving stakeholders in decision-making, he does not provide indicators for ecological sustainability and methods for relating ecological sustainability to the interests of people and economy. Spatial development plans in The Netherlands performed poorly on indicators for ecological sustainability (Termorshuizen et al. unpubl.).

So what are the reasons for the near absence of ecological sustainability in planning? One reason could be the paucity of spatially explicit ecological rules and thresholds (Opdam, Foppen and Vos 2001). Another possible reason is the limited development of ecologically based spatial concepts, which are flexible enough to make them fit into the regional context of the planning area and simple enough to be handled by non-specialists. In this chapter I will address a possible solution to the second reason, and introduce the concept of the ecosystem network. Ecosystem networks are spatial structures in the landscape, composed of patches and linear elements of a defined ecosystem type, for example wet or dry forest, or freshwater marshland (Opdam 2002). A group of ecosystem patches in a landscape will function as a network if the patches are functionally connected by exchange of individuals of species, allowing the populations in the patches to function as a meta-population. However, the scope of this paper is not to compare the pros and cons of ecosystem networks with those of other concepts. The aim of this chapter is to explore to what extent ecosystem networks can be linked to functions of the landscape. I shall mainly focus on biodiversity, but shall briefly address social and economic aspects too. Also, I will discuss how ecosystem networks may facilitate decision-making. Because most of this is still in the stage of ideas and assumptions, I shall end with some research priorities. 


\section{A knowledge model for sustainable landscape development}

If the landscape is the unit of spatial development, changed by humans for the purpose of better providing economic goods and services, then the question is how decision-making about landscape change is taking into account the principles of sustainable development. How are decisions made about the ambition level of a function (for example, how many species or how many satisfied tourists)? How about the structure of the landscape that supports that ambition level? About which functions are spatially compatible? About which conditions allow the landscape to recover from disturbances? These are very different sorts of questions, and to give them a place I propose the following conceptual landscape model (see Figure 1), which is structured according to the principles of sustainable development. The model encompasses four mutually dependent 'constructs of the landscape'. These are paralleled by the four principle currents of planning mentioned by Leitão and Ahern (2002): physical planning, economic planning, social planning and integrated planning.

1) The ecophysical landscape, the landscape viewed as a mosaic of ecosystems, is composed of an abiotic component and a biotic component. In this view, humans are actors in the landscape system, just like animals, and their action may have an impact on the ecological functioning of the landscape. For example, a large minimum number of species is required to maintain the stability of ecosystem processes in changing environments (Loreau et al. 2001). This is the landscape of spatial ecologists, of eco-hydrologists and physical geographers. The goal of research is to link the spatial pattern of the landscape to ecological and geographical functions, to determine impacts of human action, and to provide decision-makers with criteria, indicators and tools.

2) The social landscape, the landscape perceived through the eyes of humans, with its narratives and emotions, the landscape used by tourists and the landscape providing health to humans. This is the landscape of environmental psychologists, of social and medical sciences, of cultural studies and anthropology. The goal of research is to link the spatial pattern of the landscape to social, medical and psychological functions, to determine impacts of human action on these functions and to provide decision-makers with criteria, indicators and tools.

3) The economic landscape, the landscape considered as a system providing goods and services of economic value (De Groot, Wilson and Boumans 2002; Luck, Daily and Ehrlich 2003). These include the effect of increased health on labour productivity or the economic value of tourism, or the economic value of pollination (Kremen, Williams and Thorp 2002) or pest suppression (Gurr, Wratten and Luna 2003) for agriculture. This is the landscape of environmental economists. The goal of research is to link the spatial pattern of the landscape to the potential to produce goods and services, to determine impacts of human action on these functions, to determine the economic value of landscape services and to provide decision-makers with criteria, indicators and tools.

4) The decision-making landscape, the landscape as the unit of integrated planning and design. It is the landscape of spatial planners, landscape architects, politicians and the actors in decision-making.

This model makes clear what integrative landscape research is about. Integrative landscape research focuses on the interrelationships between these landscape 
constructs. The model acknowledges the interdisciplinary aspect (relations between ecological, social, economic and decision-making domains). The transdisciplinary aspect is primarily based in the decision-making domain. The goal of integrative research is to develop methods to define feasible regional goals in each domain and weight conflicting claims, to develop design methods to find sustainable solutions, to develop decision-making theory and procedures, and to organize the capacity of actors to make decisions.

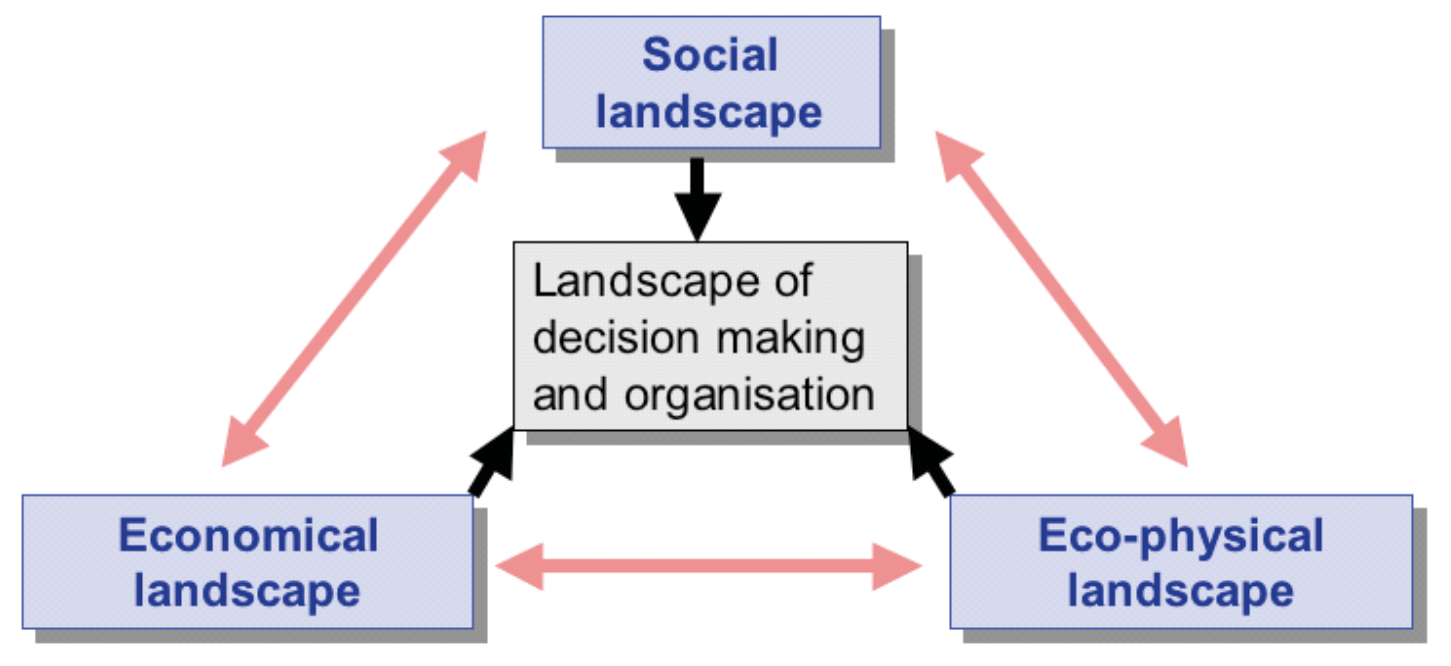

Figure 1. Representation of the four dimensions of the landscape, with their interrelations

In the next section I will discuss the role of ecosystem networks in focussing integrative research to the needs for sustainable planning.

\section{The ecosystem network as a spatial structure to integrate ecological and socioeconomic values}

Landscape development is about reallocating function-related structures. The physical structure is the concrete object of planning, and it is therefore essential to know how the dimensions and the shape of these structures support functioning. For example: a certain intensity and type of human transport require a certain density and type of road networks. In this section I argue that biodiversity-related functions are dependent on ecosystem networks. I also briefly address the question why ecosystem networks may have relevance to other landscape functions demanding spatially coherent structures at the regional scale.

From the point of view of ecology, ecosystem networks may be defined as a set of ecosystems of one type, linked into a spatially coherent system through flows of organisms, humans or water, and interacting with the landscape matrix in which it is embedded. For biodiversity, the ecosystem network is a multi-species concept. One network of woods may serve as a habitat network (as defined by Hobbs 2002; and Opdam 2002) for many species at the same time. A landscape usually contains several ecosystem types and, in consequence, several types of ecosystem network. Ecosystem networks may contain aquatic ecosystems (in which case there are flows of water, natural organisms and water tourists) or terrestrial organisms (with only organism and human flows linking the network patches). Ecosystem networks may include both patch-shaped areas and linear-shaped areas. Greenways (Ahern 2002) are a special type of network, containing linear landscape structures only. Ecosystem networks can 
be classified according to the functions they are meant for: a conservation network only aims at conserving biodiversity, a recreation network aims at tourism purposes, and so on. Ecological networks (Jongman 1995) often have a strategic-political meaning; sometimes they are just a list of legally protected areas, quite often a hybrid between conservation networks and multiple-goal networks.

What is the significance of ecosystem networks in sustainable development? In many landscapes with intensive human exploitation, the fragmentation of natural ecosystems has developed to a degree that local areas cannot support viable populations of many species (Saunders, Hobbs and Margules 1991; Kinnaird et al. 2003; Myers 2003). Opdam et al. (1995) proposed a solution to this fragmentation problem based on considering the set of local populations that form a network. Metapopulation ecology suggests that the long-term persistence of such network populations depends on the spatial cohesion of ecosystem networks (Opdam, Verboom and Pouwels 2003). The degree of cohesion of the ecosystem network determines whether or not local extinction and recolonization rates are in equilibrium, and whether the network allows the population to be resilient to stochastic demographic processes and environmental perturbations (Hanski 1999). One may say that in ecosystem networks local risks are spread over the whole network (Figure 2). An important future stress factor on a much larger scale is climate change, which entails potentially dramatic effects: for example a rise in temperature, changes in precipitation, extended periods of drought, or increased incidence of extreme events. Ecosystem networks may provide a spatial structure allowing populations to respond to these events (Opdam and Wascher 2004). Hence, ecosystem networks may be regarded as a large-scaled spatial structure required for the long-term conservation of natural resources in multifunctional landscapes.

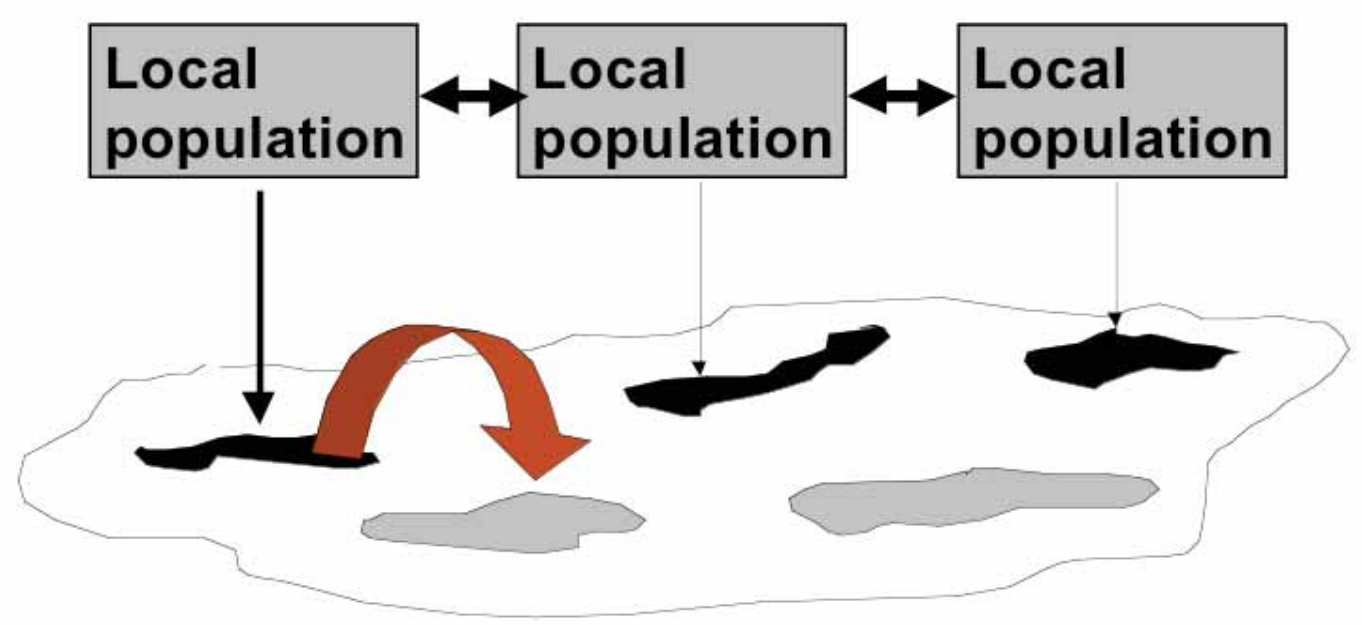

Figure 2. Illustration of the principle of spreading of local risk across the ecosystem network (based on metapopulation ecology). In a region including 5 habitat sites for a hypothetical species, three sites are actually occupied, while in two other sites for some reason (a local disturbance, chance) the species has disappeared. One of these sites is reoccupied by dispersing individuals coming from one of the local populations in the region. The second unoccupied site may follow soon, but elsewhere something may go wrong again

Can ecosystem networks be linked to social values? Do social land-use functions require large-scaled structures as well? I discuss this point using the example of recreation. Intuitively, tourist activities in a landscape require spatial cohesion. 
Tourists may cover considerable distances within or between ecosystem areas and may need both linkages and patches (Figure 3). Obviously, there should be a relationship between the perception and suitability of a landscape and, among other things, the type of ecosystems, their configuration in space, their tranquillity and accessibility (Goossen and Langers 2000). Intuitively, one may also expect the area available for recreation and the density, cohesion and configuration of ecosystems to be of value, because these features determine the capacity of a landscape for tourists to move around and the probability to encounter other tourists. Yet, to my knowledge, recreation research has not presented much evidence supporting this hypothesis, nor has it provided a detailed approach of designing ecosystem networks for recreational use and quality. Most research is focussed on behaviour and motivation of individuals, and lacks spatial explicit approaches enabling a quantified relation to landscape characteristics (Kliskey 2000; Roovers, Hermy and Gulinck 2002; Arriaza et al. 2004). For application in decision-making on sustainable development, quantified aims for recreation in an area should be defined (for various types of recreation, and acknowledging the perception of landscape quality by people). These aims are to be translated into landscape conditions: type, area and configuration of ecosystem networks.

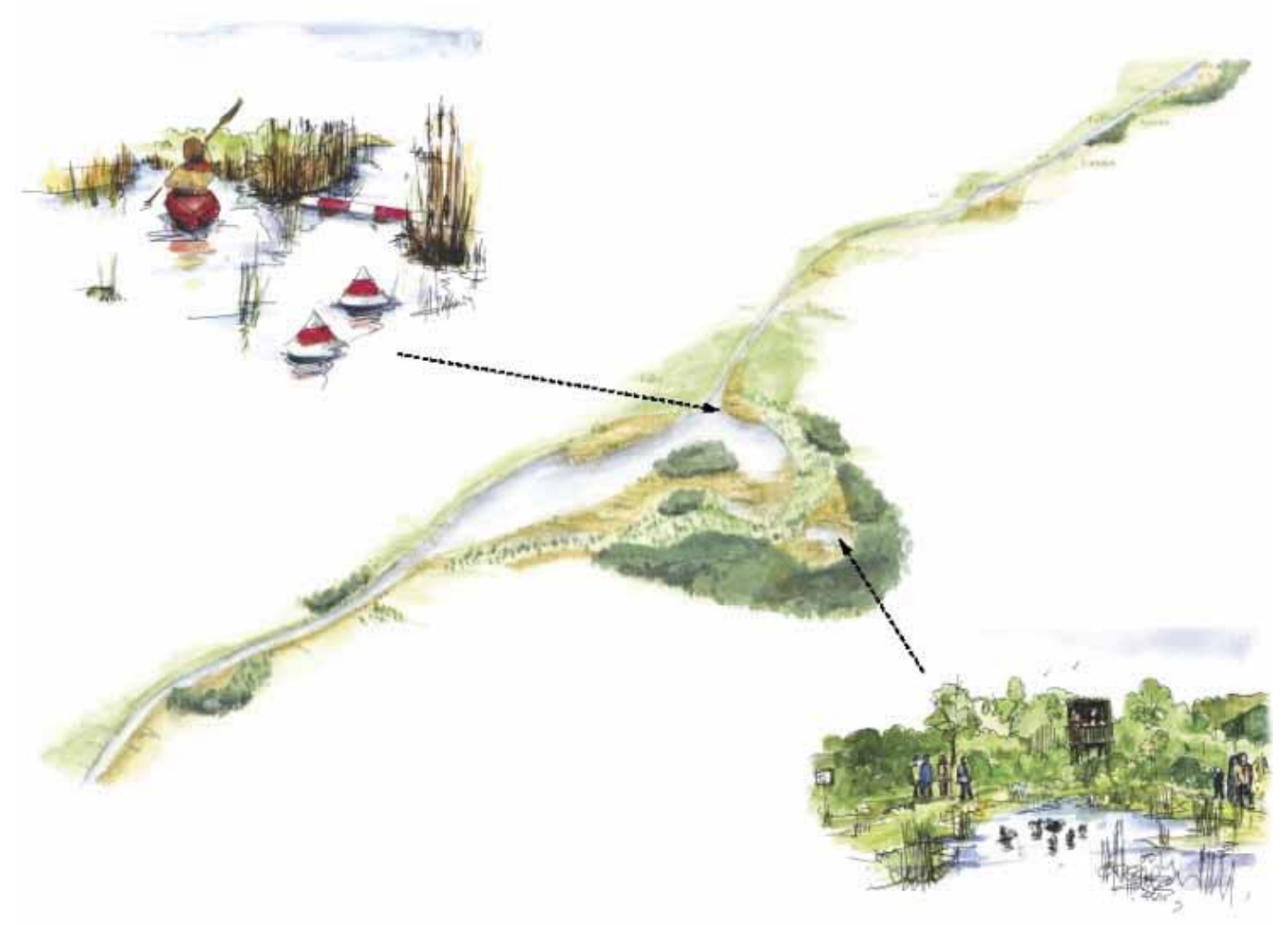

Figure 3. Representation of a planned robust corridor zone, encompassing nodes where small populations may settle, and connectivity zones. The zone is also made suitable for canoeing and walking. Nodes are planned larger than necessary in a situation without disturbance (from Broekmeijer and Steingröver 2003)

Can ecosystem networks be linked to economic values? Even though there have been numerous environmental valuation studies of biodiversity and ecosystem functions in the US and in Europe (Garrod and Willis 1992; Costanza et al. 1997; De 
Groot, Wilson and Boumans 2002), a valuation approach that can be used in a spatially explicit context has (to my knowledge) not been completed. It has been shown that extensive areas of nature, like the Dutch National Ecological Network, contribute to the regional economy and positively affect real-estate prices (Berends and Vreke 2002; Bervaes and Vreke 2004). Such data suggest that there must be links between such spatial features as type, area and configuration of ecosystems and the regional economy. In addition, the water storage and retention capacity of an ecosystem network can be expressed in terms of costs and benefits for a region.

If we could express the spatial pattern of ecosystem networks in terms of the capacity of the landscape to provide a desirable level of biodiversity and recreation, then we would have the ecophysical basis for designing ecosystem networks for a combination of functions. Where and when such functions are compatible, stakeholders with diverging interests can be united to support the development of an ecosystem network structure. This brings us to the topic of decision-making.

\section{Ecosystem networks for decision-making about ecologically sustainable landscape development}

Sustainable landscape development requires a continuing decision process about landscape change in which ecological, social and economic requirements are balanced without losing irreplaceable entities. Hence, it entails the controlled adaptation of the landscape to future needs of the society. For example, it requires that all actors in the process accept the aim of long-term persistence of (a certain level of) biodiversity. However, balancing also implies that, for the planning region, the functions end up with optimal, rather than with maximal conditions. Balancing implies negotiation, and compromises are part of the process (Kingsland 2002). So the planning process should lead stakeholders through decisions about priority ecosystem types and target species, and about the required physical conditions needed (including enough space and connectivity in the right location). Governmental laws and national conservation targets may impose constraints and opportunities in setting regional targets, whereas amounts of available space and funding, as well as support by the local stakeholders, may set limits to the conditions. Treu et al. (2000) and von Haaren (2002) stressed that in multi-actor decision-making communication is a key factor for success. I hypothesize that ecosystem networks: (1) help to focus on an ecologically relevant part of the landscape, a part that can be pictured as a concrete structure that appeals to the actors' imagination of what biodiversity needs; (2) facilitate negotiation about feasible goals and required area, configuration and location of ecosystems; and (3) can be designed in alternative options with more or less equal ecological sustainability.

Most aspects of these conjectures have not been tested thoroughly for ecosystem networks; neither do I know the conditions under which their advantages are most effectively realized. Published research in refereed journals about the role of ecological networks in effective communication is scarce, if available at all. However, Rientjes and Roumelioti (2003) undertook a survey among conservationists and policymakers in 31 European countries. They concluded that there is a wide support for the concept (at least in the European planning context), and that it has a potential to appeal to the general public as well as to specific stakeholder groups, because it can easily be explained to lay persons and made visible through maps. Von Haaren (2002) supports this view by stating that the connection of design and ecological contents 
helps to promote the acceptance of landscape plans. This was confirmed by three applications of designing with ecosystem networks with local stakeholders in Cheshire, UK (Van Rooij, Steingrover and Opdam 2003), Emilia Romagna, Italy (Van Rooij, Van der Sluis and Steingröver 2003), and the Gelderse Vallei, The Netherlands (Steingrover, pers. comm.). Stakeholders reported that the design approach based on ecosystem networks helped them to focus and made it easier to agree on common priorities. Also, they stated that ecological criteria urged them to make decisions and find solutions. Van Rooij et al. (2003) also proposed a method for interactive goal setting, based on a system of ecoprofiles (Vos et al. 2001; in press).

A key feature of ecosystem networks is that they can have different configurations and still serve the same goals. This is due to the variation in four physical features of ecosystem networks: total network area, ecosystem quality, network density and permeability of the matrix (Opdam, Verboom and Pouwels 2003). Together, these features constitute the spatial cohesion of the landscape. In planning, these four features can be used as four spatial strategies: the implication is that there are many alternative solutions to design the required dimensions and shape of an ecosystem network (Figure 4). Hence, ecosystem networks are flexible ecological structures (Opdam, Steingröver and Van Rooij in press).

\section{Network cohesion generator}

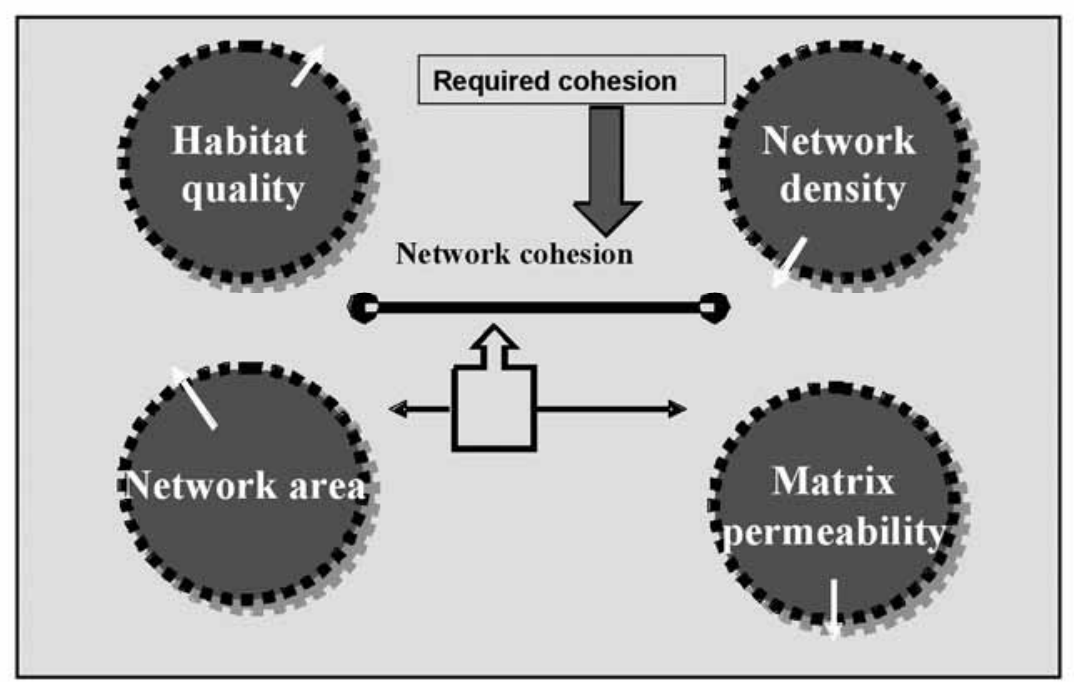

Figure 4. A spatial-cohesion generator, a virtual instrument with four knobs (for ecosystem quality, network area, network density and matrix permeability) to show that to develop the required spatial cohesion in a region several options can be generated. The arrow can be set in the right position by turning each of the four knobs, or a combination of more than one

\section{Research priorities in integrative research}

In this chapter I propose a central role for ecosystem networks in sustainable planning. Many of my thoughts are ideas and assumptions, which need to be elaborated, tested and validated. At present, there are more questions than answers. The most important questions can be classified into three groups: (i) spatial scale of the network in relation to function, (ii) quantifying the potential to deliver goods and services, and (iii) balancing different interests in the short term and long term. 


\section{Spatial scale: which function on what level?}

Species differ with respect to the spatial dimensions of their networks (Vos et al. 2001), in their capacity to move, and in the amount of habitat area they require per unit of reproduction (Vos et al. 2001; in press). Species with limited movement capacities can cover small distances of unsuitable land between habitat areas, which means that ecosystem networks can only be formed by ecosystems close to each other. Many small species cover shorter distances than large-bodied species (comparing non-flying species with non-flying ones, and flying species with flying ones). Because small species also need less area for building up viable populations, ecosystem networks for small species generally cover a smaller geographical range than networks for large ones. Verboom et al. (2001) calculated the number of individuals minimally required for a viable meta-population. These values can be transformed into values of minimal area of ecosystem networks (Table 1). For small species, sustainable ecosystem networks have a local to regional spatial scale. Larger species need ecosystem networks on larger spatial scales, which may even spread over several countries. This body of knowledge is not well incorporated into spatial planning (Jensen et al. 2000; Margules and Pressey 2000; Steiner 2000; Nakamura and Short 2001; Jim and Chen 2003), nor has been clarified whether spatial conditions that are relevant to ecological functions also apply to other landscape services. Questions to be answered are for example:

- Which ecophysical conditions should be fulfilled at different levels of scale and different levels of ambition?

- Which conditions are demanded by recreation, water management or landscape identity?

- How can knowledge on the relation between ecophysical conditions and functions be transformed into interactive decision-making methods?

Table 1. Area of multifunctional landscape (ha) required for an ecosystem network that can support a viable meta-population of selected species. The total network area varies with the presence or absence of a key patch (Verboom et al. 2001) and with the coverage of the ecosystem type in the area. Based on Verboom et al. (2001), Van Rooij et al. (2003) and expert advice. A key patch is a relatively large patch in the network with close to zero extinction probability

\begin{tabular}{|l|l|l|l|l|}
\hline & $\begin{array}{l}\text { squirrel } \\
\text { sedge warbler }\end{array}$ & $\begin{array}{l}\text { tree frog } \\
\text { nuthatch }\end{array}$ & $\begin{array}{l}\text { partridge } \\
\text { grass snake }\end{array}$ & $\begin{array}{l}\text { pine marten } \\
\text { badger }\end{array}$ \\
\hline $\begin{array}{l}\text { with key patch }(10 \% \\
\text { ecosystem coverage) }\end{array}$ & 750 & 1500 & 9000 & 120000 \\
\hline $\begin{array}{l}\text { with key patch (5\% } \\
\text { ecosystem coverage) }\end{array}$ & 1500 & 3000 & 18000 & 240000 \\
\hline $\begin{array}{l}\text { no key patch (5\% } \\
\text { ecosystem coverage) }\end{array}$ & 2000 & 5000 & 30000 & 360000 \\
\hline $\begin{array}{l}\text { no key patch (1\% } \\
\text { ecosystem coverage) }\end{array}$ & 10000 & 25000 & 150000 & 1800000 \\
\hline
\end{tabular}




\section{Thresholds and sustainability}

One of the most challenging problems to be solved in sustainable landscape development is to determine applicable spatial measures that have a causal relation to landscape functioning. There is an overwhelming choice of landscape pattern indicators, but for many of them we are still far from understanding the significance to ecological functions (Corry and Nassauer in press) or social functions. Apart from such indicators, we also need to know which critical value needs to be realized in order to get the quality of the landscape's goods and services that the decision-makers have chosen. For example, we need to tell stakeholder groups the minimum level of ecosystem network cohesion that is demanded by the target species chosen. Metapopulation theory suggests that such thresholds occur (Fahrig 2002), but attempts to elaborate such theory to applicable thresholds are scarce (see for example Verboom et al. 2001). Similar questions can be asked for the required amount of natural elements for pest control in a farm landscape, or the path density in relation to recreation intensity and quality, etc.

Another complication with determining minimum thresholds is caused by landscape change. Removing an ecosystem patch and developing a new one somewhere else means a temporary loss of carrying capacity for a species. From this notion it follows that the minimum sustainability threshold for an ecosystem network is dependent on the frequency and intensity of change. Likewise, environmental disturbances, for example climate change, also affect the position of the threshold. Populations need time to recover from disturbances, while meta-populations may need more time than non-fragmented populations (Foppen et al. 1999; Nagelkerke et al. 2002), which means that they may stay well under the carrying capacity that the landscape allows. Therefore, landscape ecology faces the challenge of defining minimum threshold levels for functional landscape indicators, which take into account the probability of large-scale and small-scale disturbances. This requires the introduction of concepts like resilience of populations and ecosystems and time-lag phenomena in research aiming at the relation between pattern and process.

Within ecosystem networks, humans can create a structure that can be changed over time without losing the conservation potential for target populations (Opdam, Steingröver and Van Rooij in press). The explanation is found in the nature of spatial cohesion, encompassing four structural components (Opdam, Verboom and Pouwels 2003). The idea is that, due to the principle of spreading of risk across the region, the ecosystem network is spatially flexible, as long as ecosystems can be developed in the region and as long as the rate of change keeps pace with the response rate of the ecosystem or population. By this flexible nature, ecosystem networks would have the potential to integrate development and conservation, and make biodiversity conservation adaptive. Again, this is a challenging field of research with great potential for application in planning. For example, how can improving quality or connectivity compensate for a decrease in network area? For which ecosystem types, under what conditions, can a lost local element be replaced by developing an element elsewhere in the network? How can rules be developed that are flexible with respect to the regional planning context?

\section{Decision-making with ecosystem networks}

If ecosystem networks are considered spatially coherent structures for conserving biodiversity in multiple-use landscapes, then the question is how decisions are being made about the total area and the configuration required for long-term persistence of 
species in the landscape. Because species differ in the area they demand for sustainability (Table 1), decisions about ecosystem network design are linked with decisions on the ambition level: the percentage of the regional biodiversity that can regionally survive increases with the total area of the network. This means that decision-making on goals (ambition level) and network design are always interlinked. The complexity of this decision further increases if one takes the surrounding area into consideration: the ecosystem network in the planning area may extend across the limits of the planning area, and goal-setting and design should consider the opportunities arising from that. This notion invokes a series of questions on the type of information on ecological conditions that can be handled by negotiating parties in a regional planning process, including tools to facilitate knowledge transfer. Brody et al. (Brody, Highfield and Carrasco 2004) proposed several challenging research goals on the collective capabilities of local jurisdictions to manage ecological systems.

More research priorities are related to combining and balancing functions, and to integrating long-term and short-term goals in decision-making. It requires that we can design ecosystem networks for a combined set of functions, and that we know the compatibility of functions. Tools must be developed to facilitate the use of scientific knowledge by non-scientists.

Decision-making in spatial planning is more and more concentrated at the regional and local level. Yet, as illustrated in Table 1 for biodiversity, public goods may require cohesive spatial structures that require supra-regional decisions. How to deal with this tension, how to encourage local decision-making to take higher-level public values into consideration, and how to coordinate decision-making among various local planning processes? This is an important field of research, from the point of view of ecology as well as socio-economy and process organization.

\section{References}

Ahern, J., 2002. Greenways as strategic landscape planning: theory and application. Wageningen University, Wageningen. Thesis

Arriaza, M., Canas Ortega, J.F., Canas Madueno, J.A., et al., 2004. Assessing the visual quality of rural landscapes. Landscape and Urban Planning, 69 (1), 115-125.

Berends, H. and Vreke, J., 2002. De rol van bos en natuur in de Achterhoek en in de Kempen: een economische waarderingsmethode getest in twee gebieden. Alterra, Wageningen. Alterra report no. 487. [http://www.alterra.nl/Internet//// Modules/pub/PDFFiles/Alterrarapporten/AlterraRapport487.pdf]

Bervaes, J.C.A.M. and Vreke, J., 2004. De invloed van groen en water op de transactieprijzen van woningen. Alterra, Wageningen. Alterra report no. 959. [http://www.alterra.nl/Internet////Modules/pub/PDFFiles/Alterrarapporten/Alte rraRapport959.pdf]

Botequilha Leitão, A. and Ahern, J., 2002. Applying landscape ecological concepts and metrics in sustainable landscape planning. Landscape and Urban Planning, 59 (2), 65-93.

Brody, S.D., Highfield, W. and Carrasco, V., 2004. Measuring the collective planning capabilities of local jurisdictions to manage ecological systems in southern Florida. Landscape and Urban Planning, 69 (1), 33-50.

Broekmeijer, M. and Steingröver, E., 2003. Design handbook robust corridors (in Dutch). Alterra, Wageningen. 
Corry, R.C. and Nassauer, J.I., in press. Limitations of using landscape pattern indices to evaluate the ecological consequences of alternative plans and designs. Landscape and Urban Planning.

Costanza, R., D'Arge, R., De Groot, R., et al., 1997. The value of the world's ecosystem services and natural capital. Nature, 387 (6630), 253-260.

De Groot, R.S., Wilson, M.A. and Boumans, R.M.J., 2002. A typology for the classification, description and valuation of ecosystem functions, goods and services. Ecological Economics, 41 (3), 393-408.

Fahrig, L., 2002. Effect of habitat fragmentation on the extinction threshold: a synthesis. Ecological Applications, 12 (2), 346-353.

Foppen, R., Ter Braak, C.J.F., Verboom, J., et al., 1999. Dutch sedge warblers Acrocephalus schoenobaenus and West-African rainfall: empirical data and simulation modelling show low population resilience in fragmented marshlands. Ardea, 87 (1), 113-127.

Forman, R.T.T., 1995. Land mosaics: the ecology of landscapes and regions. Cambridge University Press, Cambridge.

Garrod, G. and Willis, K., 1992. The amenity value of woodland in Great Britain: a comparison of economic estimates. Environmental and Resource Economics, 2 (4), 415-434.

Goossen, M. and Langers, F., 2000. Assessing quality of rural areas in the Netherlands: finding the most important indicators for recreation. Landscape and Urban Planning, 46 (4), 241-251.

Gurr, G.M., Wratten, S.D. and Luna, J.M., 2003. Multi-function agricultural biodiversity: pest management and other benefits. Basic and Applied Ecology, 4, 107-116.

Haines-Young, R., 2000. Sustainable development and sustainable landscapes: defining a new paradigm for landscape ecology. Fennia, 178 (1), 7-14.

Hanski, I., 1999. Habitat connectivity, habitat continuity, and metapopulations in dynamic landscapes. Oikos, 87 (2), 209-219.

Hobbs, R.J., 2002. Habitat networks and biological conservation. In: Gutzwiller, K.J. ed. Applying landscape ecology in biological conservation. Springer Verlag, New York, 150-170.

IUCN, UNEP and WWF, 1992. The Rio declaration on environment and development. IUCN, Gland.

Jensen, M.B., Persson, B., Guldager, S., et al., 2000. Green structure and sustainability: developing a tool for local planning. Landscape and Urban Planning, 52 (2/3), 117-133.

Jim, C.Y. and Chen, S.S., 2003. Comprehensive green space planning based on landscape ecology principles in compact Nanjing city, China. Landscape and Urban Planning, 65 (3), 95-116.

Jongman, R.H.G., 1995. Nature conservation planning in Europe: developing ecological networks. Landscape and Urban Planning, 32 (3), 169-183.

Kingsland, S., 2002. Designing nature reserves: adapting ecology to real world problems. Endeavour, 26 (1), 9-14.

Kinnaird, M.F., Sanderson, E.W., T.G., O' Brien, et al., 2003. Deforestation trends in a tropical landscape and implications for endangered large mammals. Conservation Biology, 17 (1), 245-257. 
Kliskey, A.D., 2000. Recreation terrain suitability mapping: a spatially explicit methodology for determining recreation potential for resource use assessment. Landscape and Urban Planning, 52 (1), 33-43.

Kremen, C., Williams, N.M. and Thorp, R.W., 2002. Crop pollination form native bees at risk from agricultural intensification. Proceedings of the National Academy of Science of the United States of America, 99, 16812-16816.

Linehan, J.R. and Gross, M., 1998. Back to the future, back to basics: the social ecology of landscapes and the future of landscape planning. Landscape and Urban Planning, 42 (2/4), 207-223.

Loreau, M., Naeem, S., Inchausti, P., et al., 2001. Ecology: biodiversity and ecosystem functioning: current knowledge and future challenges. Science, 294 (5543), 804-808.

Luck, G.W., Daily, G.C. and Ehrlich, P.R., 2003. Population diversity and ecosystem services. Trends in Ecology and Evolution, 18 (7), 331-336.

Margules, C.R. and Pressey, R.L., 2000. Systematic conservation planning. Nature, 405 (6783), 243-253.

Myers, N., 2003. Conservation of biodiversity: how are we doing? Environmentalist, 23 (1), 9-15.

Nagelkerke, C.J., Verboom, J., Van den Bosch, F., et al., 2002. Time lags in metapopulation responses to landscape change. In: Gutzwiller, K.J. ed. Applying landscape ecology in biological conservation. Springer Verlag, New York, 330-354.

Nakamura, T. and Short, K., 2001. Land-use planning and distribution of threatened wildlife in a city of Japan. Landscape and Urban Planning, 53 (1/4), 1-15.

Opdam, P., 2002. Assessing the conservation potential of habitat networks. In: Gutzwiller, K.J. ed. Applying landscape ecology in biological conservation. Springer Verlag, New York, 381-404.

Opdam, P., Foppen, R., Reijnen, R., et al., 1995. The landscape ecological approach in bird conservation: integrating the metapopulation concept into spatial planning. Ibis, 137 (Suppl. 1), 139-146.

Opdam, P., Foppen, R. and Vos, C., 2001. Bridging the gap between ecology and spatial planning in landscape ecology. Landscape Ecology, 16 (8), 767-779.

Opdam, P., Steingröver, E. and Van Rooij, S., in press. Ecological networks: a spatial concept for multi-actor planning of sustainable landscapes. Landscape and Urban Planning.

Opdam, P., Verboom, J. and Pouwels, R., 2003. Landscape cohesion: an index for the conservation potential of landscapes for biodiversity. Landscape Ecology, 18 (2), 113-126.

Opdam, P. and Wascher, D, 2004. Climate change meets habitat fragmentation: linking landscape and biogeographical scale level in research and conservation. Biological Conservation, 117, 285-297.

Rientjes, S. and Roumelioti, K., 2003. Support for ecological networks in European nature conservation, an indicative social map. European Centre for Nature Conservation, Tilburg. ECNC Technical Report Series. [http://www.ecnc.nl/ doc/ecnc/publicat/commpeen.pdf]

Roovers, P., Hermy, M. and Gulinck, H., 2002. Visitor profile, perceptions and expectations in forests from a gradient of increasing urbanisation in central Belgium. Landscape and Urban Planning, 59 (3), 129-145. 
Saunders, D.A., Hobbs, R.J. and Margules, C.R., 1991. Biological consequences of ecosystem fragmentation: a review. Conservation Biology, 5 (1), 18-32.

Steiner, F., 2000. The living landscape: an ecological approach to landscape planning. 2nd edn. McGraw-Hill, New York.

Treu, M.C., Magoni, M., Steiner, F., et al., 2000. Sustainable landscape planning for Cremona, Italy. Landscape and Urban Planning, 47 (1/2), 79-98.

Van Rooij, S.A.M., Steingrover, E.G. and Opdam, P.F.M., 2003. Corridors for life: scenario development of an ecological network in Cheshire County. Alterra, Wageningen. Alterra Report no. 699.

Van Rooij, S.A.M., Van der Sluis, T. and Steingröver, E.G., 2003. Networks for LIFE: development of an ecological network for Persiceto (Emilia Romagna, Italy). Alterra, Wageningen. Alterra Report 729.

Verboom, J., Foppen, R., Chardon, P., et al., 2001. Introducing the key patch approach for habitat networks with persistent populations: an example for marshland birds. Biological Conservation, 100 (1), 89-101.

Von Haaren, C., 2002. Landscape planning facing the challenge of the development of cultural landscapes. Landscape and Urban Planning, 60 (2), 73-80.

Vos, C., Opdam, P., Steingröver, E., et al., in press. Transferring ecological knowledge into a multi-actor planning process: planning and designing ecological corridors. In: Wu, J. and Hobbs, R. eds. Key topics and perspectives in landscape ecology. Cambridge University Press, New York. Landscape Ecology Series.

Vos, C.C., Verboom, J., Opdam, P.F.M, et al., 2001. Toward ecologically scaled landscape indices. American Naturalist, 157 (1), 24-41. [http://science.nature.nps.gov/im/monitor/docs\%5CVos_2001.pdf]

World Commission on Environment and Development, 1987. Our common future. Oxford University Press, Oxford. 